\title{
Correlation of iron deposition and change of gliocyte metabolism in the basal ganglia region evaluated using magnetic resonance imaging techniques: an in vivo study
}

Haodi Liu, Xiaoming Wang

Department of Radiology, Shengjing Hospital of China Medical University, Heping District, Shenyang, China

Submitted: 19 February 2014

Accepted: 16 May 2014

Arch Med Sci 2016; 12, 1: 163-171

DOI: $10.5114 /$ aoms.2016.57593

Copyright $\odot 2016$ Termedia \& Banach

\section{Abstract}

Introduction: We assessed the correlation between iron deposition and the change of gliocyte metabolism in healthy subjects' basal ganglia region, by using 3D-enhanced susceptibility weighted angiography (ESWAN) and proton magnetic resonance spectroscopy $\left({ }^{1} \mathrm{H}-\mathrm{MRS}\right)$.

Material and methods: Seventy-seven healthy volunteers (39 female and 38 male subjects; age range: 24-82 years old) were enrolled in the experiment including ESWAN and proton MRS sequences, consent for which was provided by themselves or their guardians. For each subject, the mean phase value gained by ESWAN was used to evaluate the iron deposition; choline/ creatine $(\mathrm{Cho} / \mathrm{Cr})$ and $\mathrm{ml} / \mathrm{Cr}$ ratios gained by ${ }^{1} \mathrm{H}-\mathrm{MRS}$ were used to evaluate gliocyte metabolism in the basal ganglia region of both sides. The paired t test was used to test the difference between the two sides of the basal ganglia region. Linear regression was performed to evaluate the relation between mean phase value and age. Pearson's correlation coefficient was calculated to analyze the relationship between the result of ESWAN and ${ }^{1} \mathrm{H}-\mathrm{MRS}$.

Results: There was no difference between the two sides of the basal ganglia region in the mean phase value and $\mathrm{Cho} / \mathrm{Cr}$. But in $\mathrm{ml} / \mathrm{Cr}$ the mean phase value of each nucleus in bilateral basal ganglia decreased with increasing age. There are $16 \mathrm{r}$-values between the mean phase value and $\mathrm{Cho} / \mathrm{Cr}$ and $\mathrm{ml} / \mathrm{Cr}$ in bilateral basal ganglia region. And each of all $p$-values is less than $0.001(p<0.001)$.

Conclusions: Iron deposition in the bilateral basal ganglia is associated with the change of gliocyte metabolism with increasing age. Iron deposition in each nucleus of the basal ganglia region changes with age.

Key words: 3D-enhanced susceptibility weighted angiography (ESWAN), proton MRS ( $\left.{ }^{1} \mathrm{H}-\mathrm{MRS}\right)$, iron deposition, gliocyte metabolism, basal ganglia region.

\section{Introduction}

Current studies have found that the main region of iron deposition in the brain is the basal ganglia region (including the caudate nucleus, globus pallidus, putamen, and thalamus) [1-4]. During the onset and progression of various neurodegenerative diseases such as Alzheimer's disease, Huntington's disease, and Parkinson's disease, abnormal changes in iron deposition may be observed in the basal ganglia region, and these changes are associated with the disease course [5-7]. Iron is

\author{
Corresponding author: \\ Xiaoming Wang MD \\ Department of Radiology \\ Shengjing Hospital \\ of China Medical University \\ No. 36, Sanhao Street \\ Heping District \\ Shenyang 110004 , China \\ Phone: +86 18940251024 \\ Fax: +86 2423929902 \\ E-mail:wangxm024@163. \\ com
}


stored in ferritin and transferrin found in gliocytes in the basal ganglia region [8-10]. Under normal circumstances, age and gender may influence iron metabolism in gliocytes, and iron concentrations in the intracerebral microenvironment may be regulated by a feedback mechanism. However, under pathological conditions, iron acts with the Fenton reaction, resulting in the production of free hydroxyl radicals responsible for neuronal damage [11] and proliferation of gliocytes. Therefore, iron deposition in the basal ganglia region is closely related to gliocyte metabolism.

The methods for quantitatively conducting in vivo studies of iron deposition using magnetic resonance imaging are as follows: the spin echo sequence is used to obtain relaxation time mapping, and T2, R2 (1/T2) values and FDRI (field dependent transverse relaxation rate increase) obtained from mapping are used to reflect brain iron content [12, 13]; the gradient echo (GRE) sequence is used to obtain magnetic field imaging, which can be used to acquire $T 2^{*}$ or $R 2^{*}\left(1 / T 2^{*}\right)$ values to measure brain iron $[3,14]$. 3D-enhanced susceptibility weighted angiography (ESWAN) uses 3D-GRE sequences in combination with post-processing to obtain phase images. Phase values calculated by phase position are used to quantitatively determine brain iron $[5,15,16]$. The disadvantage of using a changing relaxation time to measure brain iron is that tissue relaxation time can be affected by several major factors that include an external asymmetric magnetic field caused by iron deposition and an internal asymmetric magnetic field caused by water (spin-spin effect). However, there is a great difference in water content between different brain tissues (the difference in water content between pallium and white matter is $12 \%$ ), and the difference can affect the specificity of T2 and R2 [17]. Current studies are mainly using $\mathrm{T} 2^{*}$ and $\mathrm{R} 2^{*}$ values to analyze brain iron. The use of gradient echo sequence has shortened the scanning time and increased the background field variations caused by iron. However, static magnetic field non-homogeneity, air and bone interface artifacts and other factors can also affect background field variations. The presence of these noise signals can reduce the accuracy of parameters [18]. The ESWAN used in this study is a type of SWI (susceptibility weighted imaging) technology. Better than traditional SWI, ESWAN uses three-dimensional T2*-based multiecho acquisition to acquire high spatial resolution phase images, with resolution up to $1 \mathrm{~mm} \times 1 \mathrm{~mm}$ $\times 1 \mathrm{~mm}$ even though the R2* image thickness is only $5 \mathrm{~mm}$ [19]. Brain iron content can be measured using this rich data phase imaging, which is roughly eight times more sensitive than using T2 [20]. ESWAN can also provide a high signal noise ratio due to its own post-processing technologies, including high-pass filtering, which can reduce noises caused by air-bone interface artifacts or static field non-homogeneity and provide more specificity in measuring brain iron deposition. The disadvantages of ESWAN are that it can increase the incidence of motion artifacts and the scanning process takes more time. In addition to iron, there are other paramagnetic ions in the brain, such as copper and manganese. However, according to Schenck [21], these are less likely to be detected in susceptibility enhanced MRI.

Quantitative analysis of a material's metabolism at a specific position may be conducted using spectral lines obtained by proton MRS $\left({ }^{1} \mathrm{H}-\mathrm{MRS}\right)$ scanning and provides information regarding metabolism in neurons and gliocytes [22-24]. The metabolite choline (Cho), located at 3.22 ppm of the spectral line, is an indicator of cell membrane synthesis and degradation [25], and is considered as a marker of intracerebral cell density [26]. Studies have proven that both the absolute value of Cho and the $\mathrm{Cho} / \mathrm{Cr}$ (choline/creatine) ratio are positively correlated with gliocyte activity $[27,28]$. Myo-inositol (ml) peaks at $3.6 \mathrm{ppm}$ of the spectral line and can be identified in spectral scanning using the short TE sequence [29]. Myo-inositol may regulate the penetration function of gliocytes. In early studies, $\mathrm{ml}$ was considered to exist only in gliocytes [30], and was therefore used as a gliocyte marker. Also, the concentration of $\mathrm{ml}$ may reflect the status of gliocyte metabolism. Creatine $(\mathrm{Cr})$, located at $3.03 \mathrm{ppm}$, is used as an internal standard to correct for differences, because its concentration in the brain is stable. Therefore, in this study, we used the $\mathrm{Cho} / \mathrm{Cr}$ and $\mathrm{ml} / \mathrm{Cr}$ ratios to determine the status of gliocyte metabolism in the brain. LCModel software was used to analyze results by using endogenous water as an internal reference, and metabolite concentrations in a spatial model as the external reference to achieve absolute quantification of metabolites. This technique is superior to the use of other post-processing software for quantitative analysis of metabolites.

We used ESWAN to evaluate iron deposition in each gray matter nucleus of the basal ganglia region. Also, absolute values of $\mathrm{Cho}, \mathrm{ml}$, and $\mathrm{Cr}$ obtained by proton MRS were used to calculate the $\mathrm{Cho} / \mathrm{Cr}$ and $\mathrm{ml} / \mathrm{Cr}$ values, which reflect gliocyte metabolism in the basal ganglia region. The correlation between these two results was investigated to further study the relationship between gliocyte metabolism and iron deposition in the studied region.

\section{Material and methods}

\section{Subjects}

From June 2011 to November 2012, a total of 77 volunteers were recruited and imaged with 
normal conventional sequencing, ESWAN and ${ }^{1} \mathrm{H}-\mathrm{MRS}$. The ages of the subjects ranged from 24 to 82 years (mean: $44.4 \pm 17.3$ years); 38 were male and 39 were female. All subjects were right-handed, consumed a normal diet, had no history of chronic long-term use of iron agents, no systemic infectious disease history, no nervous system disease, cancer, mental illness, surgery or history of trauma. The subjects were divided into 6 groups (1-6) according to age: group 1 (20-29 years, $n=15)$; group 2 (30-39 years, $n=12$ ); group 3 (40-49 years, $n=14)$; group 4 (50-59 years, $n=14)$; group 5 (60-69 years, $n=10$ ); group 6 ( $\geq 70$ years, $n=12$ ). A signed informed consent form was obtained from each subject or subject guardian prior to imaging, and all parties agreed that data obtained could be used for the purposes of the study. This study was reviewed and approved by the Ethics Committee of Shengjing Hospital, China Medical University.

\section{MR examination and method}

All subjects were imaged with a 3.0 Tesla MRI system (Signa, HDxt, General Electric Healthcare, Milwaukee, WI, USA), with an 8-channel array coil. Routine sequence imaging was performed for all subjects and included axial T2WI (TR $=3520 \mathrm{~ms}$, $\mathrm{TE}=102 \mathrm{~ms}, \mathrm{ETL}=20$, matrix size $=320 \times 256)$ and FLAIR $(\mathrm{TR}=8000 \mathrm{~ms}$, TE $=165 \mathrm{~ms}, \mathrm{TI}=750 \mathrm{~ms}$, matrix size $=256 \times 192)$. This imaging was used to exclude the existence of potential pathological findings in the basal ganglia region. Axial T2WI, sagittal T2WI (TR $=612 / \mathrm{ms}, \mathrm{TE}=102 \mathrm{~ms}, \mathrm{ETL}=24$, matrix size $=416 \times 256)$, and coronal $\mathrm{T} 2 \mathrm{WI}$ $(\mathrm{TR}=11220 \mathrm{~ms}, \mathrm{TE}=102 \mathrm{~ms}, \mathrm{ETL}=24$, matrix size $=640 \times 224)$ scans were used in combination for spectral scanning (Figure 1). ESWAN images were obtained by high resolution 3D-spoiled gradient recalled echo (3D-SPGR), flip angle 15, TE $8 \mathrm{~ms}$, TR 49.2 ms, matrix size $448 \times 320$, slice thickness $1.6 \mathrm{~mm}$, anterior commissure-posterior commissure (AC-PC) line, 66 slices in total, acquisition time $4 \mathrm{~min}$ to $6 \mathrm{~min}$. Three mutually orthogonal T2-weighted images were used to locate volumes of interest (VOI) in halves. The region of interest (ROI) of the basal ganglia region is shown on the axial image, which was $5 \mathrm{~mm}$ below the anterior and posterior commissures. Coronal and sagittal images were used to micro switch the position of the ROI [31]. The basic principle of VOI includes the most basal ganglia structure while avoiding the lateral ventricle on the same side. Point resolved spectroscopy (PRESS) was used for data acquisi-
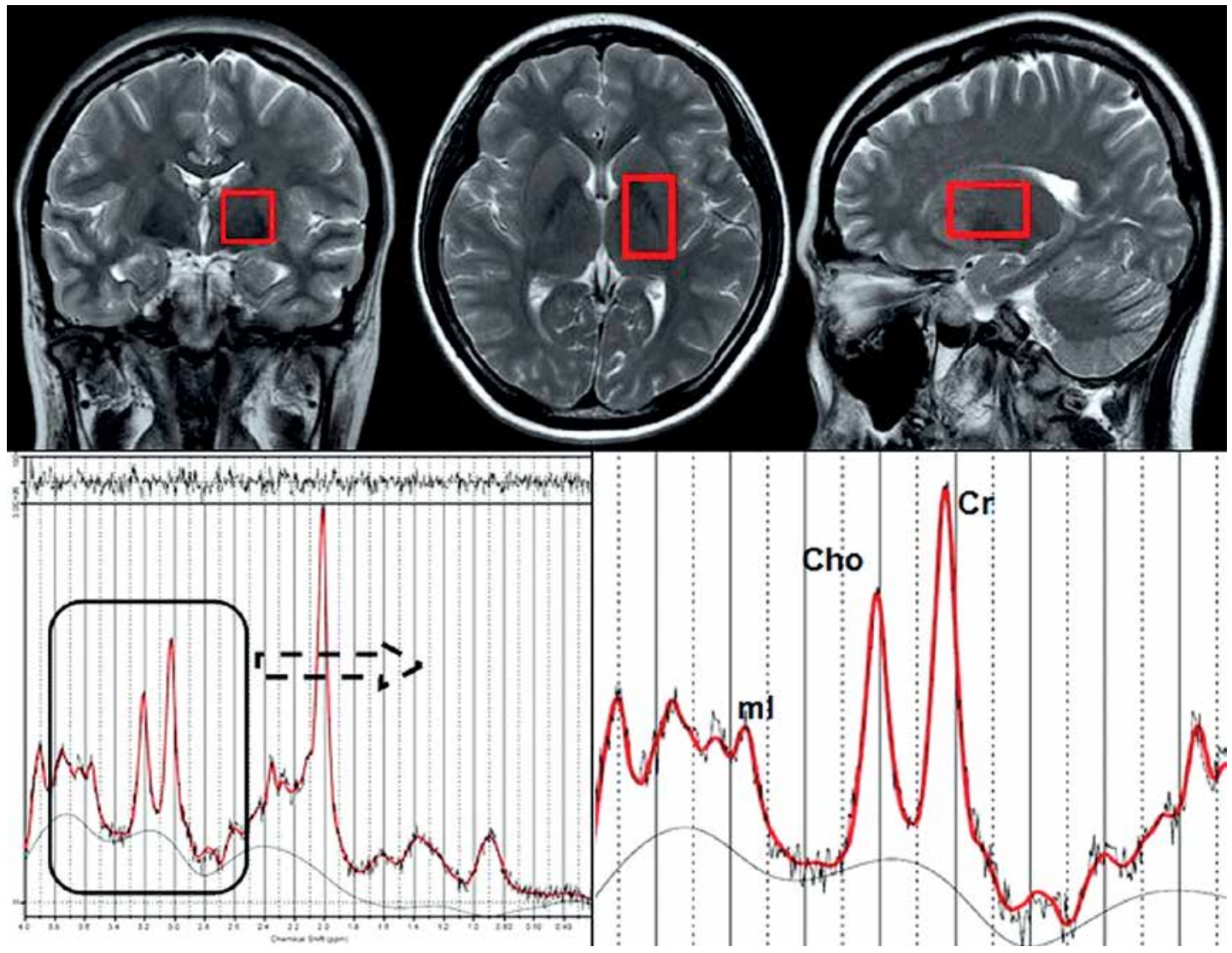

Figure 1. Voxel placement in basal ganglia region (size of voxel is $20 \mathrm{~mm} \times 20 \mathrm{~mm} \times 30 \mathrm{~mm}$ ) and spectrum of the voxel above

Cho-choline, $\mathrm{Cr}$-creatine, $\mathrm{ml}$ - myo-inositol. 
tion (TR 1500 ms, TE 35 ms, NEX 8), with an acquisition time of 4 min $20 \mathrm{~s}$. After pre-scanning, the full width at half maximum (FHWM) was $<9 \mathrm{~Hz}$, and water suppression was $\geq 95 \%$.

\section{Image post-processing and measurement}

ESWAN post-processing: All original ESWAN images were sent to Functool 9.4.05a software (GE Healthcare) of Advantage Workstation 4.4 (Sun Microsystems, Santa Clara, CA, USA) for image post-processing. First, image denoising was performed for all original images (the filtration range was expanded to the external edge of the skull), high-pass filtering $(64 \times 64)$ was done to eliminate phase distortion caused by field non-homogeneity [32], and paired phase images and magnetic moment images were obtained after completing calculations and used to determine localization. One slice in the middle, or one slice higher or lower of the bilateral basal ganglia was selected to draw the ROIs, including the caudate nucleus (CA), globus pallidus (GP), putamen (PU), and thalamus (TH) (Figure 2). When drawing an ROI, the outer edge of the nucleus was followed, and high density artifacts at the edge were avoided. Each nucleus was measured 3 times, and a second group of measurements was performed at the same site after an interval of 1 week. The recorded values were used to calculate the mean phase value of each nucleus [5, 15]

MRS data post-processing: All original MRS data were sent to LCModel (Stephen Provencher, Oakville, Ontario, Canada) for processing. Under conditions of a short echo time (TE), this software could autocorrect and compare the data with those of a baseline group. It could also differentiate the peak values of various substances by re- ferring to endogenous water, and obtain absolute concentration values for the metabolites. Records of readings and calculations of $\mathrm{Cho} / \mathrm{Cr}$ and $\mathrm{ml} / \mathrm{Cr}$ ratios are shown in Figure 1.

\section{Statistical analysis}

SPSS 20.0 software was used to analyze data, and all measurements are expressed as the $x \pm$ SD. One-way analysis of variance was applied to analyze intergroup differences of mean phase value in the caudate nucleus, globus pallidus, putamen, and thalamus regions, and the $\mathrm{Cho} / \mathrm{Cr}$ and $\mathrm{ml} / \mathrm{Cr}$ values of bilateral basal ganglia regions. A paired $t$ test was used to analyze differences of mean phase value in various nuclei in bilateral basal ganglia regions, and differences in $\mathrm{Cho} / \mathrm{Cr}$ and $\mathrm{ml} / \mathrm{Cr}$ values. Linear regression analysis was used to analyze correlations of the mean phase value of various nuclei in bilateral basal ganglia regions with age. Pearson's correlation coefficient was used to express the correlation of $\mathrm{Cho} / \mathrm{Cr}$ and $\mathrm{ml} / \mathrm{Cr}$ ratios. Pearson's correlation coefficient was also used to express the correlation of mean phase values of various nuclei in bilateral basal ganglia regions with $\mathrm{Cho} / \mathrm{Cr}$ and $\mathrm{ml} / \mathrm{Cr}$ values. The correlation $\mathrm{co}-$ efficient $(r)$ obtained was subjected to the $t$ test, and $p<0.05$ indicates statistical significance.

\section{Results}

The differences in mean phase values for the caudate nucleus, globus pallidus, putamen, and thalamus of bilateral basal ganglia regions of various groups, and the $\mathrm{Cho} / \mathrm{Cr}$ and $\mathrm{ml} / \mathrm{Cr}$ ratios of bilateral basal ganglia regions of various groups were statistically significant (Table I). However, there were no significant differences in the phase values of various nuclei in bilateral basal ganglia
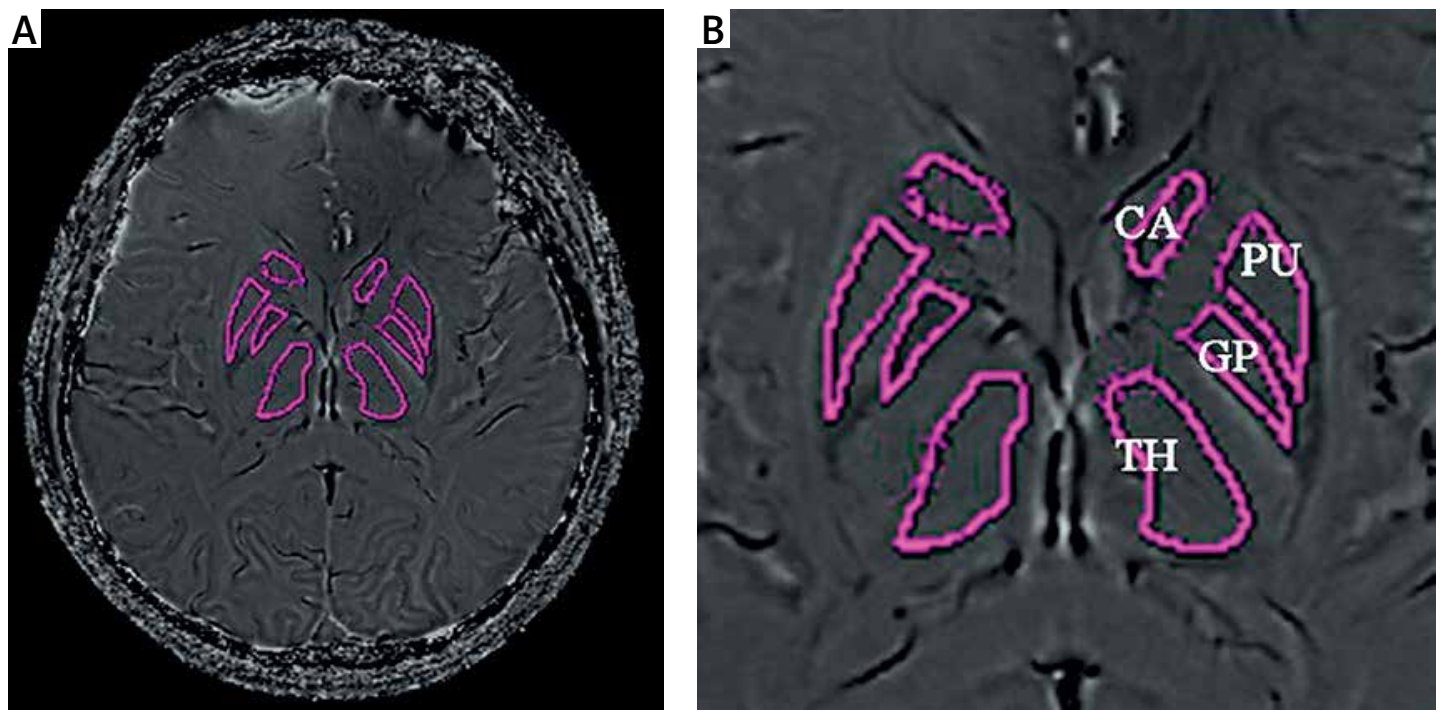

Figure 2. The phase image (A) and the ROI of CA, PU, GP and TH (B)

$C A$ - caudate nucleus, GP-globus pallidus, $P U$ - putamen, $T H$ - thalamus. 
regions. The order of mean phase values for each nucleus was as follows (from lowest to highest): globus pallidus, putamen, caudate nucleus, and thalamus. A histogram of the mean phase value of each nucleus in each group showed that the mean phase value declined with age (Figures 3 and 4).

$\mathrm{ml} / \mathrm{Cr}$ values in bilateral basal ganglia regions were significantly different, while there was no difference in $\mathrm{Cho} / \mathrm{Cr}$ values between the right and left sides (Table I). Cho/ $\mathrm{Cr}$ and $\mathrm{ml} / \mathrm{Cr}$ values from the same side were correlated (Figure 5), with correlation coefficients $(r)$ of 0.605 for the right side and 0.671 for the left side. From Table II, the mean phase values of the caudate nucleus, globus pallidus, putamen, and thalamus in bilateral regions were negatively correlated with $\mathrm{Cho} / \mathrm{Cr}$ and $\mathrm{ml} / \mathrm{Cr}$ values, and the correlation coefficient of the $\mathrm{ml} / \mathrm{Cr}$ ratio and mean phase value of various nuclei was larger than that for the $\mathrm{Cho} / \mathrm{Cr}$ value. The correlation coefficient of the mean phase value and $\mathrm{Cho} / \mathrm{Cr}$ and $\mathrm{ml} / \mathrm{Cr}$ for the caudate nucleus, globus pallidus, and putamen was larger than that for the thalamus.

\section{Discussion}

A comparison of mean phase values of various nuclei showed that the globus pallidus had the lowest phase value, while the thalamus had the highest phase value (Figure 2). According to the formulas $\Delta \psi$ (phase) $=-r \Delta \mathrm{BTE}$ ( $r$ signifies gyromagnetic, $\Delta B$ signifies variation of field intensi- ty among different tissues, and TE signifies echo time) and $\Delta B=c V \Delta \mathrm{xB}_{0}$ ( $c$ signifies iron content, $V$ signifies the voxel volume, and $\Delta x$ signifies intermolecular magnetic sensitivity differences induced by the presence of iron), we know that at the same TE level, there was a negative correlation between $c$ and $\Delta \psi$, which represents the correlation between the content of iron and the phase value [17]. Therefore, the order of iron content in each nucleus of the basal ganglia region was as follows (from highest to lowest): globus pallidus, putamen, caudate nucleus, and thalamus, which agrees with the results of previous histological studies [1]. Wang [15] reached the same conclusion when studying changes of iron deposition in the caudate nucleus and globus pallidus with age using ESWAN techniques. Therefore, it appears that the phase value obtained by ESWAN is a reliable method for evaluating iron content in brain tissues. Although research has shown that ESWAN technology for evaluating the accuracy of phase values of brain iron deposition is lower than R2* [33], the primary subjects evaluated have been babies in whom myelination has not yet matured, and the brain tissue water content is high. These factors affect the T2* $\left(1 / \mathrm{R}^{*}\right)$ signal. The subjects in the present study are healthy adults (age greater than 20 years), and we believe that the two results are not contradictory. Hallgren [1] reported that iron deposition in the globus

Table I. Summary of mean phase value, $\mathrm{ml} / \mathrm{Cr}$ ratio and $\mathrm{Cho} / \mathrm{Cr}$ ratio in bilateral basal ganglia. Summary of $\mathrm{MR}$ parameter (mean phase value of ESWAN and $\mathrm{ml} / \mathrm{Cr}$, Cho/ $\mathrm{Cr}$ ratios of ${ }^{1} \mathrm{H}-\mathrm{MRS}$ ) and the result of statistical analysis

\begin{tabular}{|c|c|c|c|c|c|c|c|c|}
\hline Parameter & & $N$ & Mean & SD & $F$ & $P_{1}$ & $t$ & $P_{2}$ \\
\hline \multirow[t]{2}{*}{ CA } & $R$ & 77 & -0.0259 & 0.0087 & 174.8 & $<0.05$ & & \\
\hline & $\mathrm{L}$ & 77 & -0.0259 & 0.0089 & 193.5 & $<0.05$ & 0.943 & $>0.05$ \\
\hline \multirow[t]{2}{*}{ GP } & $R$ & 77 & -0.6726 & 0.2093 & 285.6 & $<0.05$ & & \\
\hline & $\mathrm{L}$ & 77 & -0.6726 & 0.2071 & 288.1 & $<0.05$ & 0.99 & $>0.05$ \\
\hline \multirow[t]{2}{*}{ PU } & $R$ & 77 & -0.0492 & 0.0194 & 302.4 & $<0.05$ & & \\
\hline & $\mathrm{L}$ & 77 & -0.0494 & 0.0194 & 315.9 & $<0.05$ & 0.104 & $>0.05$ \\
\hline \multirow[t]{2}{*}{$\mathrm{TH}$} & $R$ & 77 & 0.0015 & 0.0018 & 72.74 & $<0.05$ & & \\
\hline & L & 77 & 0.0015 & 0.0017 & 57.92 & $<0.05$ & 0.554 & $>0.05$ \\
\hline \multirow[t]{2}{*}{ Cho/Cr } & $\mathrm{R}$ & 77 & 0.2751 & 0.027 & 16.44 & $<0.05$ & & \\
\hline & $\mathrm{L}$ & 77 & 0.2738 & 0.027 & 19.11 & $<0.05$ & 1.417 & $>0.05$ \\
\hline \multirow[t]{2}{*}{$\mathrm{ml} / \mathrm{Cr}$} & $R$ & 77 & 0.5695 & 0.076 & 55.38 & $<0.05$ & & \\
\hline & $\mathrm{L}$ & 77 & 0.5619 & 0.074 & 58.34 & $<0.05$ & 3.752 & $<0.05$ \\
\hline
\end{tabular}

$P_{1}$ is the result of one-way analysis of variance; $t$ and $P_{2}$ are the results of paired test between right and left side of basal ganglia. $P_{1}<0.05$ means that there was no significant difference between the groups of these parameters. $P_{2}>0.05$ means that there was no significant difference between the right side and left side in basal ganglia of these parameters. CA - caudate nucleus, GP - globus pallidus, $P U$ - putamen, $T H$-thalamus. $R$ is short for right side and $L$ is left side. 
A

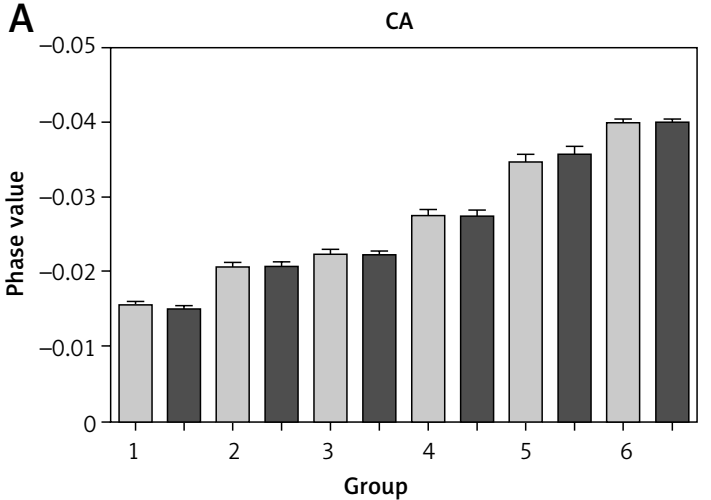

C

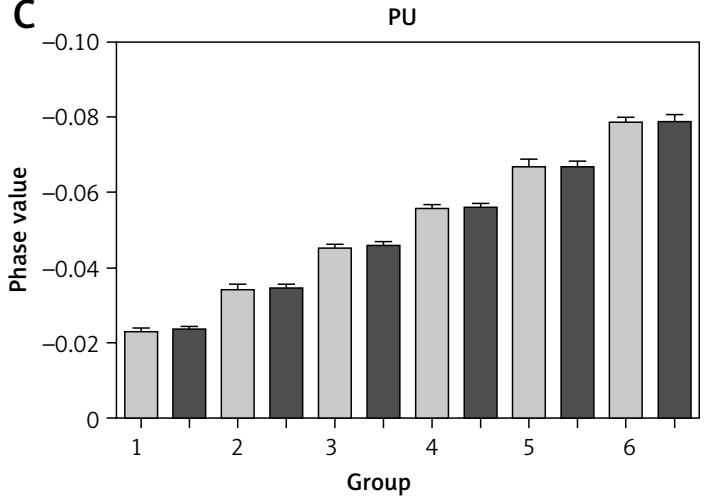

B

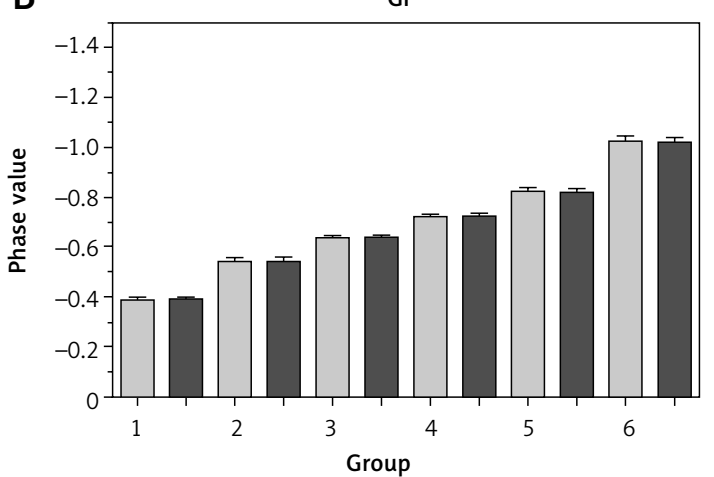

D

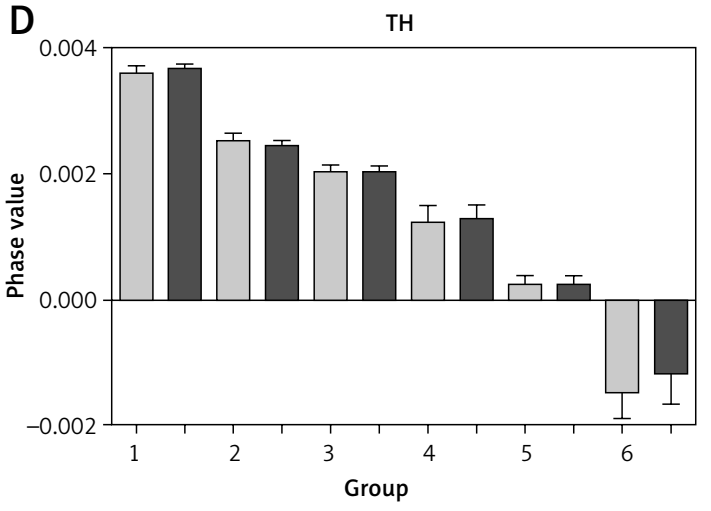

Figure 3. Histogram of mean phase value in each nucleus

$C A$ - caudate nucleus, GP-globus pallidus, $P U$ - putamen, $T H$-thalamus.

pallidus occurred during youth, and that values appeared to be relatively constant during a period of 40 years. In our study, we found that the phase value declined with age, which indicated that iron deposition continued regardless of age, and even during old age. Additionally, a study conducted by Aquino et al. [3] also supported the findings of our current research. A study conducted by Xu et al. [16] investigating iron deposition in different encephalic regions of right handed subjects found that there was more iron deposition in the substantia nigra on the left side, and speculated that this might be related to a vigorous metabolism. In our current study, we found no difference of phase value between the left and right nuclei, which indicates that there was no difference in iron deposition between the left and right basal ganglia regions. However, there was a difference in $\mathrm{ml} / \mathrm{Cr}$ values between the left and right basal ganglia regions. In addition to the reports described above, we believe there are differences in metabolism between the basal ganglia of bilateral sides, but these processes have no influence on bilateral deposition of iron.

The analysis of correlations between iron deposition in homolateral nuclei and $\mathrm{Cho} / \mathrm{Cr}$ and $\mathrm{ml} /$ $\mathrm{Cr}$ values showed that the mean phase value of each nucleus was strongly correlated with metabolites. In combination with the linear correlation between iron deposition in each nucleus with age, we believe that iron deposition in the basal ganglia region may be related to changes in gliocyte metabolism with age. A study performed by Dringen [34] found that gliocytes may absorb, store, and release iron, and accurately regulate iron transportation and content, which suggests that gliocytes are closely associated with iron metabolism. A study conducted by Mrak et al. [28] found that gliocyte numbers increased and metabolism became more vigorous with increasing age. Additionally, Connor et al. [8] reported that the subcortical zone and basal ganglia are rich in gliocytes containing ferritin, and the number of these gliocytes increases with age. These findings suggest that under normal circumstances, iron deposition in each nucleus of the basal ganglia region is associated with gliocyte metabolism. In this study, the correlation analysis of $\mathrm{Cho} / \mathrm{Cr}$ and $\mathrm{ml} / \mathrm{Cr}$ ratios with the phase value of each nucleus found that the correlation coefficient for the $\mathrm{ml} / \mathrm{Cr}$ ratio with the phase value was larger. In the current spectrum of studies on metabolism in the human brain, there are more discussions of $\mathrm{ml}$ than of Cho. This is because in the early stage of a study, the spectrum of a single voxel is always obtained by long TE (e.g. $135 \mathrm{~ms}$ ), and only small amounts of metabolites (including $\mathrm{N}$-acetylaspartic acid 
A

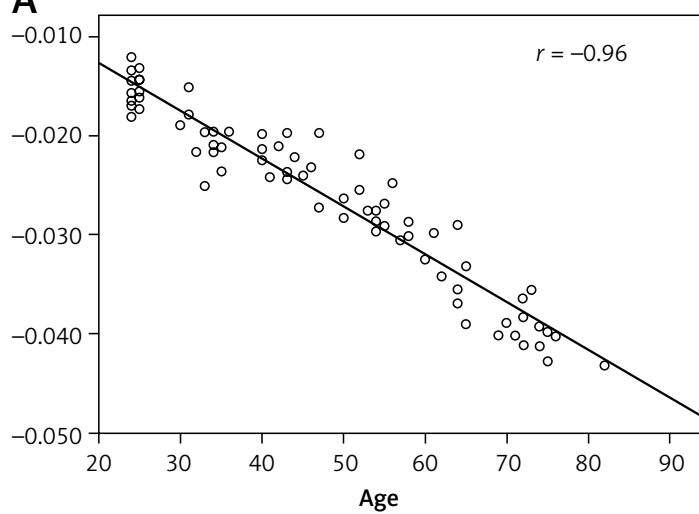

C

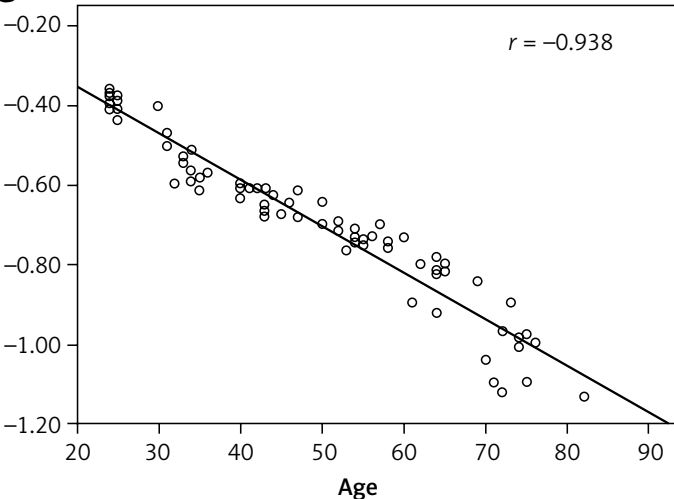

E

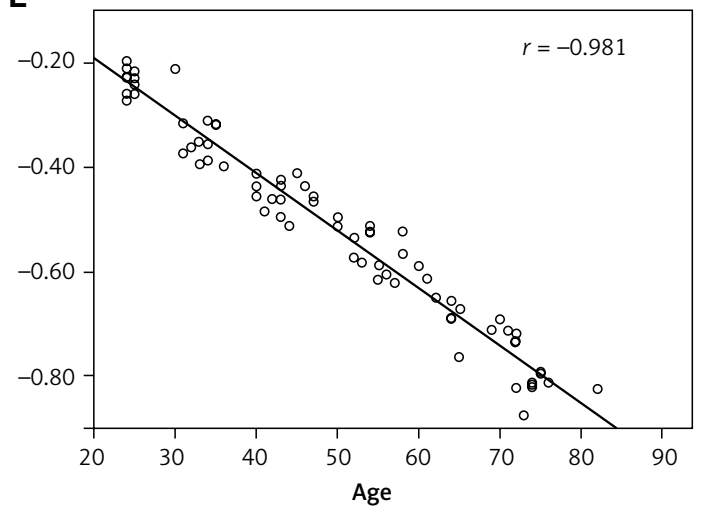

G

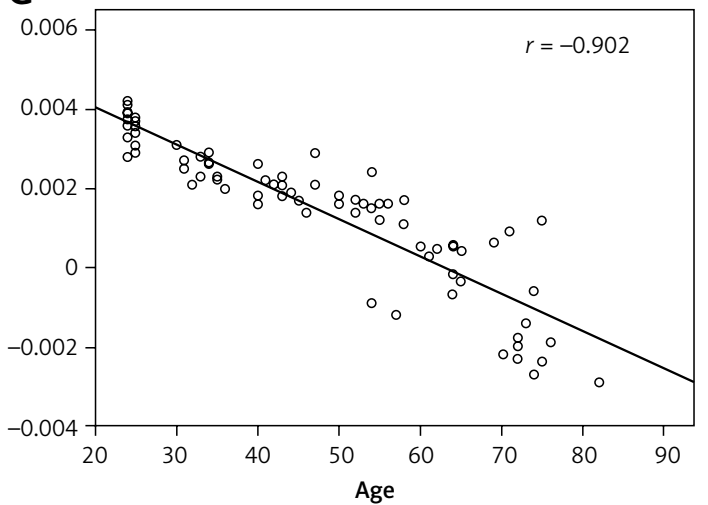

B

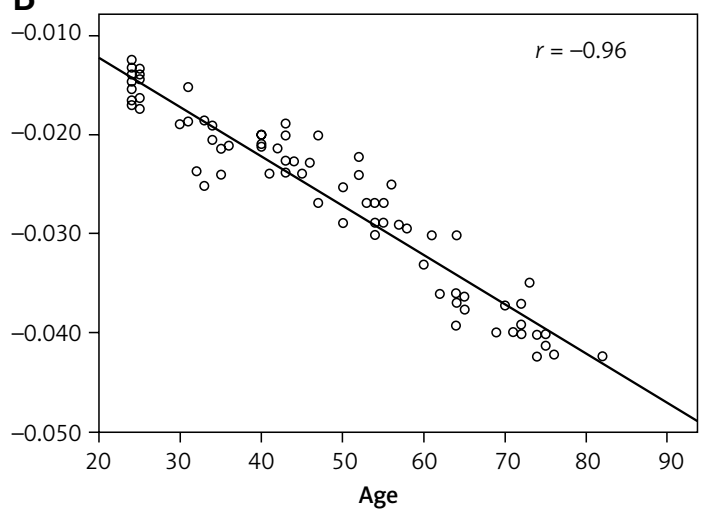

D

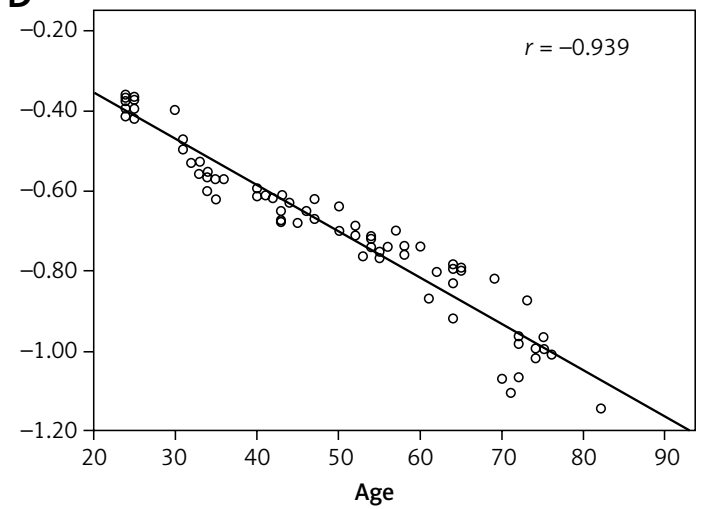

F

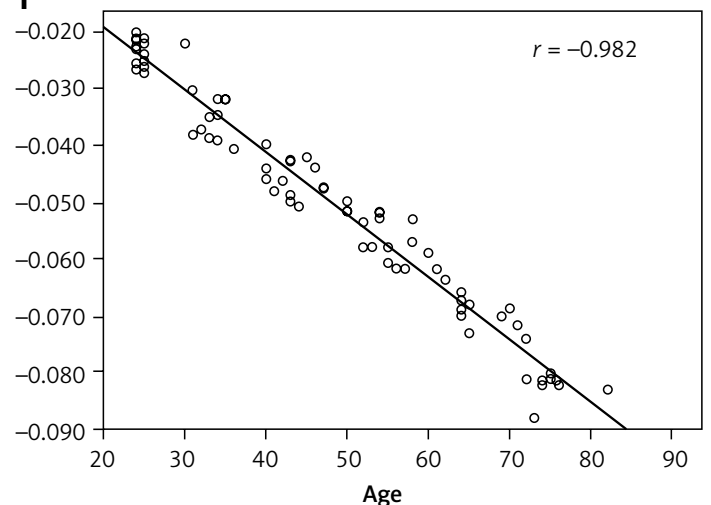

$\mathrm{H}$

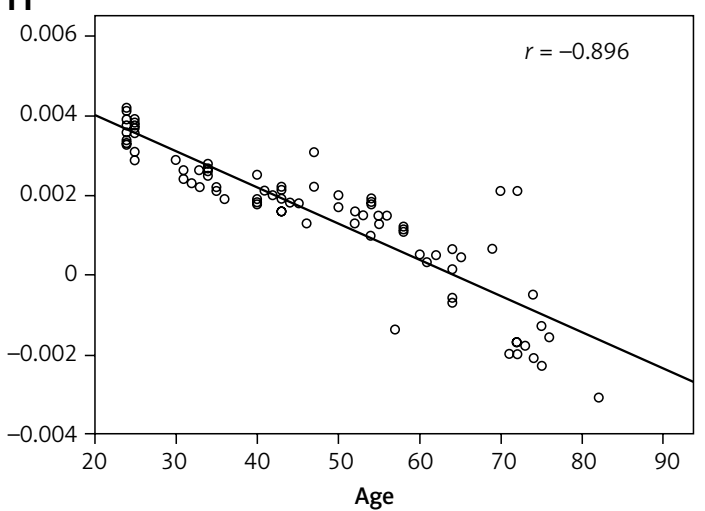

Figure 4. A-H are the regression lines of mean phase value and age. A is for the right caudate nucleus, B for the left, $\mathbf{C}$ is for the right globus pallidus, $\mathbf{D}$ for the left, $\mathbf{E}$ is for the right putamen, $\mathbf{F}$ for the left, $\mathbf{G}$ is for the right thalamus, $\mathrm{H}$ for the left 
A

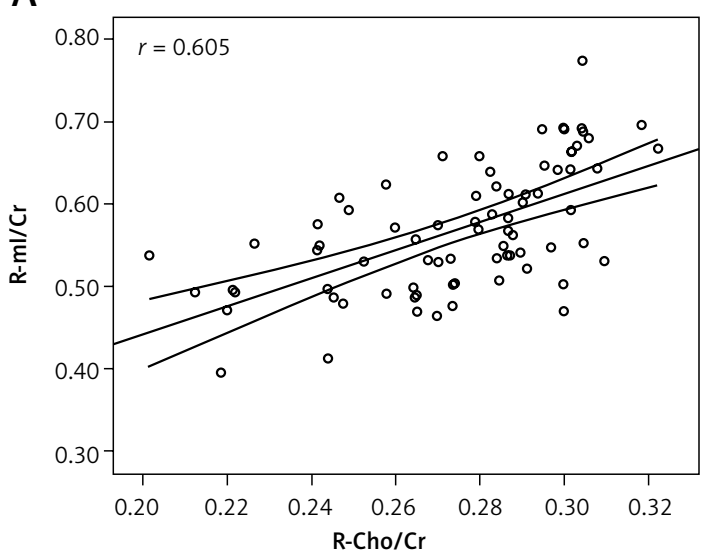

B

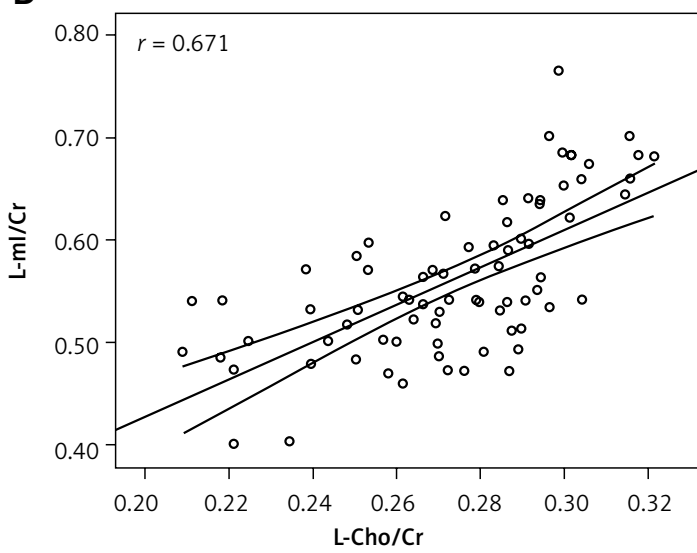

Figure 5. Scatter plot correlation diagram of the ipsilateral basal ganglia between $\mathrm{ml} / \mathrm{Cr}$ and $\mathrm{Cho} / \mathrm{Cr}$ ratios. $\mathrm{A}$ is the right side and $\mathbf{B}$ is the left side

Table II. The correlation coefficient of mean phase value and $\mathrm{ml} / \mathrm{Cr}$ ratio, mean phase value and $\mathrm{Cho} / \mathrm{Cr}$ ratio in bilateral basal ganglia

\begin{tabular}{|lllll|}
\hline Parameter & \multicolumn{3}{c}{$\mathrm{R}$} & \multicolumn{2}{c|}{$\mathrm{L}$} \\
\cline { 2 - 5 } & $\mathrm{Cho} / \mathrm{Cr}$ & $\mathrm{ml} / \mathrm{Cr}$ & $\mathrm{Cho} / \mathrm{Cr}$ & $\mathrm{ml} / \mathrm{Cr}$ \\
\hline CA & -0.653 & -0.847 & -0.703 & -0.843 \\
\hline GP & -0.651 & -0.879 & -0.685 & -0.885 \\
\hline PU & -0.679 & -0.870 & -0.724 & -0.887 \\
\hline TH & -0.625 & -0.775 & -0.672 & -0.798 \\
\hline
\end{tabular}

$C A$ - caudate nucleus, GP - globus pallidus, $P U$ - putamen, $T H-$ thalamus. The absolute values of the correlation coefficient were higher than 0.7 .

(NAA), Cho, and $\mathrm{Cr}$ ) are observed. However, PRESS, with a short TE, makes analysis of more metabolites possible, including analysis of myo-inositol (ml) [35]. Choline is a main component of cell membranes, and choline levels are considered to be an important index of cell density. Also, an abnormal increase in Cho levels may indirectly reflect the proliferation of gliocytes. As a marker of gliocyte metabolism, $\mathrm{ml}$ may directly reflect gliocyte metabolism and proliferation, and is widely used for classification and grading of gliocytomas $[36,37]$. However, there is no current study that demonstrates a correlation of $\mathrm{ml}$ changes with gliocytes in normal brain tissues. We believe that the $\mathrm{ml} / \mathrm{Cr}$ ratio is superior to the $\mathrm{Cho} / \mathrm{Cr}$ ratio for reflecting gliocyte metabolism.

There are some limitations in our research. We used $\mathrm{Cr}$ as an internal reference value to eliminate individual differences among subjects. However, the influence of absolute $\mathrm{Cr}$ values on metabolism was not separately discussed. A study performed by Reyngoudt et al. [38] proved that a change of $\mathrm{Cr}$ levels with age is associated with gliocyte metabolism. Therefore, when an absolute value of $\mathrm{Cr}$ is discussed as a separate factor, it might have some influence on the results of the study, which would be further discussed in future studies. When ESWAN is used for a study of iron deposition, calcification of a ROI is a potential factor which may compromise the accuracy of a phase value (especially for the globus pallidus). Although regions of calcification and peripheral artifacts induced by phase inversion should be avoided as much as possible when defining a ROI, they are still important factors that may compromise the accuracy of a measurement.

In conclusion, with increasing age, iron deposition in the bilateral basal ganglia becomes associated with the change of gliocyte metabolism. The iron content in each nucleus of the basal ganglia region changes with age, and there is no statistically significant difference between the left and right side of the brain. The $\mathrm{ml} / \mathrm{Cr}$ value is superior to the $\mathrm{Cho} / \mathrm{Cr}$ value for examining gliocyte metabolism in normal human brains.

\section{Acknowledgments}

This study was supported by a grant from the National Natural Science Foundation of China (81000467), a grant from the Free Research Foundation of Shengjing Hospital (200802), and a grant from Liaoning Province (2010-696).

\section{Conflict of interest}

The authors declare no conflict of interest.

\section{References}

1. Hallgren B, Sourander P. The effect of age on the nonhaemin iron in the human brain. J Neurochem 1958; 3 : 41-51.

2. Schenker C, Meier D, Wichmann W, et al. Age distribution and iron dependency of the $T 2$ relaxation time in the globus pallidus and putamen. Neuroradiology 1993 . 35: 119-24

3. Aquino D, Bizzi A, Grisoli $M$, et al. Age-related iron deposition in the basal ganglia: quantitative analysis in healthy subjects. Radiology 2009; 252: 165-72. 
4. Bilgic B, Pfefferbaum A, Rohlfing T, Sullivan EV, Adalsteinsson E. MRI estimates of brain iron concentration in normal aging using quantitative susceptibility mapping. Neuroimage 2012; 59: 2625-35.

5. Zhu WZ, Zhong WD, Wang W, et al. Quantitative MR phase-corrected imaging to investigate increased brain iron deposition of patients with Alzheimer disease. Radiology 2009; 253: 497-504.

6. Bartzokis G, Tishler TA. MRI evaluation of basal ganglia ferritin iron and neurotoxicity in Alzheimer's and Huntington's disease. Cell Mol Biol 2000; 46: 821-33.

7. Sian-Hülsmann J, Mandel S, Youdim MB, Riederer P. The relevance of iron in the pathogenesis of Parkinson's disease. J Neurochem 2011; 118: 939-57.

8. Connor JR, Menzies SL, St Martin SM, Mufson EJ. Cellular distribution of transferrin, ferritin, and iron in normal and aged human brains. J Neurosci Res 1990; 27: 595-611.

9. Connor JR, Menzies SL, Burdo JR, Boyer PJ. Iron and iron management proteins in neurobiology. Pediatr Neurol 2001; 25: 118-29.

10. Malyszko J, Koc-Zorawska E, Levin-laina N, et al. Iron metabolism in hemodialyzed patients - a story half told? Arch Med Sci 2014; 10: 1117-22.

11. Alexandrov PN, Zhao Y, Pogue Al, et al. Synergistic effects of iron and aluminum on stress-related gene expression in primary human neural cells. J Alzheimers Dis 2005; 8: 117-27.

12. Chen JC, Hardy PA, Clauberg M, et al. T2 values in the human brain: comparison with quantitative assays of iron and ferritin. Radiology 1989; 173: 521-6.

13. Schenker C, Meier D, Wichmann W, Boesiger P, Valavanis A. Age distribution and iron dependency of the T2 relaxation time in the globus pallidus and putamen. Neuroradiology 1993; 35: 119-24.

14. Gelman N, Gorell JM, Barker PB, et al. MR imaging of human brain at 3.0 T: preliminary report on transverse relaxation rates and relation to estimated iron content. Radiology 1999; 210: 759-67.

15. Wang D, Li WB, Wei XE, Li YH, Dai YM. An investigation of age-related iron deposition using susceptibility weighted imaging. PLoS One 2012; 7: e50706.

16. Xu X, Wang Q, Zhang M. Age, gender, and hemispheric differences in iron deposition in the human brain: an in vivo MRI study. Neuroimage 2008; 40: 35-42.

17. Haacke EM, Cheng NY, House MJ, et al. Imaging iron stores in the brain using magnetic resonance imaging Magn Reson Imaging 2005; 23: 1-25.

18. Sukstanskii AL, Yablonskiy DA. Theory of FID NMR signal dephasing induced by mesoscopic magnetic field inhomogeneities in biological systems. J Magn Reson 2001; 151: 107-17.

19. Hayashida Y, Kakeda S, Hiai Y, et al. Diagnosis of intracranial hemorrhagic lesions: comparison between 3D-SWAN (3D T2*-weighted imaging with multi-echo acquisition) and 2D-T2*-weighted imaging. Acta Radiol 2014; 55: 201-7.

20. Haacke EM, Ayaz M, Khan A, et al. Establishing a baseline phase behavior in magnetic resonance imaging to determine normal vs. abnormal iron content in the brain. J Magnet Resonance Imaging 2007; 26: 256-64.

21. Schenck JF. Magnetic resonance imaging of brain iron. J Neurol Sci 2003; 207: 99-102.

22. Bates TE, Strangward M, Keelan J, Davey GP, Munro PM, Clark JB. Inhibition of $\mathrm{N}$-acetylaspartate production: implications for $1 \mathrm{H}-\mathrm{MRS}$ studies in vivo. Neuroreport 1996; 7: 1397-400.
23. Bitsch A, Bruhn H, Vougioukas V, et al. Inflammatory CNS demyelination: histopathologic correlation with in vivo quantitative proton MR spectroscopy. AJNR 1999; 20: 1619-27.

24. Glanville NT, Byers DM, Cook HW, Spence MW, Palmer FB. Differences in the metabolism of inositol and phosphoinositides by cultured cells of neuronal and glial origin. Biochim Biophys Acta 1989; 1004: 169-79.

25. Couillard-Despres S, Vreys R, Aigner L, Van der Linden A. In vivo monitoring of adult neurogenesis in health and disease. Front Neurosci 2011; 67: 1-10.

26. Miller BL, Chang L, Booth R, et al. In vivo $1 \mathrm{H}-\mathrm{MRS}$ choline: correlation with in vitro chemistry/histology. Life Sci 1996; 58: 1929-35.

27. Urenjak J, Williams SR, Gadian DG, Noble M. Proton nuclear magnetic resonance spectroscopy unambiguously identifies different neural cell types. J Neurosci 1993; 13: 981-9.

28. Mrak RE, Griffin WS. Glia and their cytokines in progression of neurodegeneration. Neurobiol Aging 2005; 26: 349-54.

29. Gruber S, Pinker K, Riederer F, et al. Metabolic changes in the normal ageing brain: consistent findings from short and long echo time proton spectroscopy. Eur J Radiol 2008; 68: 320-7.

30. Brand A, Richter-Landsberg C, Leibfritz D. Multinuclear NMR studies on the energy metabolism of glial and neuronal cells. Dev Neurosci 1993; 15: 289-98.

31. Fayed N, Lopez Del Hoyo Y, Andres E, et al. Brain changes in long-term zen meditators using proton magnetic resonance spectroscopy and diffusion tensor imaging: a controlled study. PLoS One 2013; 8: e58476.

32. Ishimori Y, Monma M, Kohno Y. Artifact reduction of susceptibility-weighted imaging using a short-echo phase mask. Acta Radiol 2009; 50: 1027-34.

33. Ning N, Zhang L, Gao J, et al. Assessment of iron deposition and white matter maturation in infant brains by using enhanced T2 star weighted angiography (ESWAN): R2* versus phase values. PLoS One 2014; 9: e89888.

34. Dringen R, Bishop GM, Koeppe M, Dang TN, Robinson SR. The pivotal role of astrocytes in the metabolism of iron in the brain. Neurochem Res 2007; 32: 1884-90.

35. Gruber S, Pinker K, Riederer F, et al. Metabolic changes in the normal ageing brain: consistent findings from short and long echo time proton spectroscopy. Eur J Radiol 2008; 68: 320-7.

36. Bulik M, Jancalek R, Vanicek J, Skoch A, Mechl M. Potential of MR spectroscopy for assessment of glioma grading. Clin Neurol Neurosurg 2013; 115: 146-53.

37. Hattingen E, Raab P, Franz K, Zanella FE, Lanfermann H, Pilatus U. Myo-inositol: a marker of reactive astrogliosis in glial tumors? NMR Biomed 2008; 21: 233-41.

38. Reyngoudt H, Claeys T, Vlerick L, et al. Age-related differences in metabolites in the posterior cingulate cortex and hippocampus of normal ageing brain: a $1 \mathrm{H}-\mathrm{MRS}$ study. Eur J Radiol 2012; 81: 223-31. 